\title{
Intergenerational support and depression among Chinese older adults: do gender and widowhood make a difference?
}

\author{
MAN GUO*, IRIS CHI $\dagger$ and MERRIL SILVERSTEIN
}

\begin{abstract}
Using four-wave panel data of 1,327 older adults in rural China, this study examined potential gender and marital status differences in the relationships between three forms of intergenerational support (monetary, instrumental and emotional support) and the level of depression of the older adults. Results from a pooled time-series fixed-effects model showed that receiving and providing monetary support had a comparable beneficial effect on mothers and fathers, but mothers benefited more psychologically than fathers from closer relationships with their children. Exchanges in instrumental support was not related to either mothers' or fathers' level of depression. Widowhood further affected the gendered relationships between support and depression in that recently widowed fathers had a significantly higher level of depression when they received more monetary support from their children. In contrast, providing monetary support to children was associated with a significantly higher level of depression among recently widowed mothers. We explained the findings in the context of familial and gender norms in the Chinese culture and temporal needs for family support that link with bereavement coping stages among older adults. We argued that the gender and marital status patterns observed in this study are attributive to more fundamental differences in men's and women's social positions in the Chinese society.
\end{abstract}

$\boldsymbol{K E Y} \boldsymbol{W O R D S}$ - intergenerational support, depression, gender differences, widowhood, China, older parents.

\section{Introduction}

Gender is significantly associated with support-relevant interactions in later life (Turner and Marino 1994). Abundant evidence has shown that older men and women differ in both quantitative and qualitative aspects of

* School of Social Work, University of Iowa, Iowa City, USA.

$\dagger$ School of Social Work, University of Southern California, Los Angeles, USA.

$\$$ Maxwell School of Citizenship and Public Affairs and School of Social Work, Syracuse University, USA. 


\section{Man Guo et al.}

family support (Antonucci and Akiyama 1987). Gender may also confound the relationship between support and psychological wellbeing. Differential vulnerability theory suggests that compared to men, women may be more psychologically responsive to support because they are usually more relationship-oriented and more actively involved in various forms of support (Uchino, Cacioppo and Kiecolt-Glaser 1996).

Such a gendered relationship may be interrupted by life-changing events such as loss of a spouse. Widowhood creates psychological distress in the surviving spouse and children, which in turn influences their relationships (Carr et al. 2001). Studies have showed that losing a spouse increased parent-child contact and the amount of support received by older adults (Eggebeen 1992; Roan and Raley 1996; Utz et al. 2004). Men seem to be affected by widowhood to a greater extent than are women, as wives are often the only confidants of married men, whereas women usually have someone besides their husbands to turn to for support (for a review of gender differences in adjustment to widowhood, see Stroebe, Stroebe and Schut 2001). Such a gender difference in the experience of widowhood suggests that the role of intergenerational support in older adults' adjustment to loss may be more important for bereaved fathers than mothers. If so, the assumption of women being more responsive to support might be weakened or reversed upon widowhood. In short, the influence of intergenerational support on older adults' mental health may be affected by both the gender and marital status of the older person.

Although studies of family relations and later life wellbeing have commonly included gender and marital status as control variables, the gender-patterned vulnerability theory remains largely untested in intergenerational relations. Even fewer studies have examined the potential interaction between gender and marital status in the relation between intergenerational support and parental wellbeing. But such information not only helps to contribute to a more complete understanding of laterlife wellbeing in a family context, but is also crucial to help identify older adults with particular attributes that are at risk of adverse mental health. In addition, existing studies on gender, intergenerational support and later-life wellbeing have used samples primarily from developed countries in the West (e.g. Fiori and Denckla 2012; Sonnenberg et al. 2013). These findings may not be generalised to family relations in different cultural contexts, nor do they fully capture the experiences of older adults from economically deprived countries or regions (Kawachi and Berkman 2001; Thoits 2011).

Rural China, for instance, provides a very different and interesting setting for such investigations. Chinese society, in general, and rural China, in particular, is characterised by strong family norms of filial piety, that is, 
responsibilities of adult children to care for their ageing parents. Together with older people's limited personal resources and underdeveloped pension system in rural China, it means that intergenerational relations may play a more salient role in the lives and wellbeing of Chinese rural elders as compared to their counterparts in Western developed countries. In addition, rural China is a patrilineal society in nature with more strict gender roles than most Western societies. This means that older men and women in rural China may have quite different positions in the family than those in the West, which in turn affect the ways they are involved in and influenced by intergenerational relations, as well as the potential consequences of widowhood on intergenerational relations and individual wellbeing.

In short, to provide a long-lacking perspective from economically underdeveloped areas that have more traditional family norms, this study used four-wave longitudinal data collected in a relatively poor region in rural China to investigate (a) whether three forms of intergenerational support (i.e. monetary, instrumental and emotional support) affect the psychological wellbeing of older men and women differently, and (b) whether any gendered patterns in these relationships are altered upon widowhood.

\section{Literature review}

\section{Gender differences in intergenerational support in late life}

Researchers have extensively documented gender differences in intergenerational support among older parents. Compared to fathers, mothers are often more involved in various intergenerational exchanges (Antonucci and Akiyama 1987). Such gender-patterned transfers seem to vary by the type of support. A comparison of older adults in eight Asian countries found that overall older women were more likely to depend on family members for economic support, whereas work and pension were the major source of income for older men (Ofstedal, Reidy and Knodel 2004). Instrumental support (i.e. practical, tangible support) received by older adults seems to depend greatly on their needs and available resources regardless of gender (Silverstein, Gans and Yang 2006). But men usually receive more instrumental support, whereas women receive more intimate and interactive emotional support (Reevy and Maslach 2001; Umberson et al. 1996). Closer ties between mothers and children may lead to children providing more emotional support to mothers than to fathers (Ofstedal et al. 2004).

Flow of support is typically reciprocal. Ageing parents, especially mothers, often provide adult children with significant amounts of tangible support 


\section{Man Guo et al.}

such as help with child care and household chores (Ingersoll-Dayton, Neal and Hammer 2001). Provision of monetary support to children is contingent upon older adults' economic resources. While most exchanges of financial assistance are from the older to younger generations in the United States of America (Silverstein et al. 2002), older adults in less-developed countries/regions such as rural China are far more likely to receive than to provide intergenerational financial support (Zhang, Guo and Zheng 2012). Limited research on gender differences in downward monetary transfers in families has shown that mothers were more likely to give monetary support to children than fathers and such support was more stable in marital disruptions such as divorce (Agree et al. 2002; Furstenberg, Hoffman and Shrestha 1995).

\section{Does gender moderate the effect of support on psychological wellbeing?}

Research suggests that social support may not affect the psychological wellbeing of women in the same way it does for men. Differential exposure theory suggests that throughout their lives women tend to experience more frequent exposures to stressful events as a result of their relatively disadvantaged status in the social structure (Janzen 1998; Rieker and Bird 2000). One such stressor is financial strain. Women tend to earn less than men over the lifecourse, leading to their higher likelihood of experiencing economic strains and consequently mental disorders (Rosenfield 1989; Wu and DeMaris 1996). As women usually occupy a more significant role within families and broader social networks, they are also more likely to experience stressors related to family relations than men (Shye et al. 1995). Women's greater exposure to enduring financial and emotional life strains suggests that the stress-buffering effects of social support may have a greater impact on women than on men.

Differential vulnerability theory further suggests that the same level of support may have a greater psychological effect on women than on men (Rieker and Bird 200o; Uchino, Cacioppo and Kiecolt-Glaser 1996). Such a difference is partly due to the gender differences in self-identity constructions. Women usually experience themselves more often through their relationships with others (Cyranowski et al. 2000; Williams 1993). For example, they usually invest more time and emotion in their families and commonly organise their identities around their ability to keep family connected and to fulfil family obligations. Self-evaluations of these role performances affect women's global self-esteem or worth, which in turn is associated with psychological wellbeing (Thoits 2011). As such, women may react more strongly than men to family relations because of the meanings these relations have for their sense of identity (Haines, Beggs and Hurlbert 
2008). Women and men also differ in how they experience social relations. Because women's social relations often involve more intimacy, empathy and emotional disclosure, being in a relationship and involved in support exchanges may also benefit women more than men (Elliott 2001; Turner and Marino 1994). Overall, both the differential exposure and vulnerability theories predict a greater psychological reactivity to family relations in women than in men.

Empirical findings regarding this assumption are mixed and have been largely limited to emotional support. While some studies reported a lack of gender differences in the relation between received support and psychological wellbeing among older adults (Hann et al. 2002; Turner and Marino 1994; Umberson et al. 1996; van Daalen, Sanders and Willemsen 2005), others found that either older men (Robb, Small and Haley 2008; Sonnenberg et al. 2013) or women were more responsive to received support (Fiori and Denckla 2012; Husaini et al. 1991). With regard to providing support, it can be more health protective than receiving support (Brown et al. 2003). Again, empirical evidence is mixed, reporting either a lack of gender differences (Fiori and Denckla 2012) or that women were more reactive to support provision (Shumaker and Hill 1991). The only Chinese study that we are aware of reported that feelings of relatedness were more predictive of life satisfaction among older women than older men (Cheng and Chan 20o6).

Overall, the mixed findings reviewed above may be attributed to the different ways in which support was assessed in the studies (e.g. network size, numbers of confident, received versus perceived support). Different resources and needs of older adults who had diverse social and economic backgrounds in these studies (e.g. United States, The Netherlands, Japan, Hong Kong) may also contribute to the inconclusive findings. In sum, the assumption that intergenerational support affects elderly women more than elderly men deserves further explorations that carefully distinguish different types of support and take into consideration the socio-economic and cultural contexts of support transfers. Studies on economically disadvantaged older adults who have limited resources for exchanges are particularly needed.

\section{Widowhood, intergenerational support and parental wellbeing}

A most well-documented feature of widowhood is that it usually has a substantially stronger effect on men than on women (Lee et al. 2001; Stroebe, Stroebe and Schut 2001). Older women are found to be less vulnerable for depression than older men when they lose their partners (Sonnenberg et al. 2000; Van Grootheest et al. 1999). Although married 
women usually have higher rates of depression than married men, such a gender difference diminishes or disappears among bereaved persons (Friedman et al. 2003; Stroebe and Stroebe 1987). Men's greater vulnerability in widowhood might be explained by their greater reliance on spouses for intimacy, social participation and emotional support. Thus, it is more difficult for them to maintain previous levels of social support upon widowhood, leading to a more significant consequence of partner loss among men than women (Umberson, Wortman and Kessler 1992). The greater impact of widowhood on men than on women suggests that the assumption that women are more responsive to social support might be weakened or even reversed upon widowhood. Takizawa et al. (2006) found that under stressful circumstances in middle age, providing and receiving social support were only associated with males', not females', lower level of depression. This finding points to the importance of considering both gender and marital status when examining the relationship between family support and psychological wellbeing in later life.

Widowhood usually attracts more support from adult children in older people (Utz et al. 2004). Both widowers and widows were found to be more likely to confide in at least one child than their married counterparts, suggesting that the quality and extent of interactions with children may increase when widowed (Connidis and Davis 1992). Examining overall support from children among widowers versus widows yielded mixed findings. A large-scale survey in the Netherlands showed that the difference between support to mothers and fathers (i.e. mothers receive more support) increased upon widowhood, possibly because it reduced the support from children that widowers used to receive through the mother (Kalmijn 2007). In contrast, a French study reported that fathers received more family support than mothers after being widowed (Delbès and Gaymu 2002). These mixed findings may result from examining overall instead of individual aspects of support in the two studies, because widowhood often creates needs for different support among fathers and mothers. The gender-patterned family responsibilities, i.e. men usually specialise in the financial and legal aspects of household tasks and women specialise in the household chores and caregiving, suggest that the widowed person may be more likely to depend on children for the type of assistance that was previously performed by the lost partner. This assumption was supported by Gu and Liang (2000), who found that the primary cause of depression was financial strains among widows but was strains associated with household management among widowers. Studies have also shown that widows are more likely than widowers to rely on adult children for financial support and legal advice, the typical duties of their late husbands (Ha et al. 20o6; Sobieszczyk, Knodel and Chayovan 2003). 
The flow of intergenerational support is not solely upward following the loss. Mothers also engage in more reciprocal relationships with their children than do fathers upon widowhood (Carr and Utz 2004). They offer assistances with child care or household chores and maintain balance in intergenerational relations by resisting their children's help when it becomes over-protective and by limiting their own expectations for support (Van den Hoonaard 2001).

The relationship between intergenerational support and psychological wellbeing among widowed parents also varies by the recency of widowhood. Bereavement stages, i.e. the initial adjustment or late bereavement phase, affects the consequences of the support received (Bankoff 1983). According to Bankoff (1983), in the early phase of bereavement, the newly widowed tend to withdraw from reality, generally paying little attention to social relations. They may even be hostile to well-meaning attempts to help. As the grief of spousal loss lessens over time, the widowed move towards resuming their normal lives, gradually reorganising and rebuilding social relations and social interactions. Meaningful communications and support can then be resumed at this stage. This framework implies that the emotional reaction to support provided by children may differ among newly bereaved parents and those in later stages of bereavement.

Taken together, the above literature suggests that (a) widowhood may reduce the gender difference in the responsiveness to intergenerational support, (b) such change may differ across different types of support, and (c) the bereavement stage of widowhood affects the influence of support on parental wellbeing.

\section{Family relations in rural China}

About 6o per cent of Chinese older populations live in rural areas (National Statistics Bureaus of China 2014). On average, Chinese rural elderly have a larger household size (3.6 versus 3.2 ) and are more likely to live with their children than their urban counterparts (Zeng and Wang 2003). Although adult children in most societies are the major sources of old-age support, in China, filial responsibility of adult children entails a complex series of duties which may include co-residence, food provision, and physical, financial and emotional care of the parents (Zhan 2004). Children's responsibility for caring for their parents is even written in the Chinese law (Chou 2011). Support from adult children is especially crucial for Chinese rural elders who often have very limited personal resources and formal services. In 2014, the disposable personal income of rural residents (¥10,489, equal to US $\$ 1,648$ ) was less than half of that of urban residents ( $¥ 28,844$, equal to US $\$ 4,615$ ) (National Statistics Bureaus of China 2014). 
In addition, compared to 74 per cent of urban elderly who receive pensions, only 5 per cent of rural elderly do so (China Research Center on Ageing 2009). The lack of protection of formal services makes adult children the most viable source of old-age support for Chinese rural elders. A national study reported that 73 per cent of Chinese rural elders received monetary support from children, compared to less than half $(47 \%)$ of their urban counterparts who did so (Pei and Pillai 1999).

Family relations in rural China are also characterised by significant downward instrumental support in the form of child care. Massive rural-to-urban migration in China creates millions of skipped-generation households, in which rural elderly, in particular older women, shoulder the responsibilities of child care on behalf of their migrant children (Cong and Silverstein 2011). Providing such care seems to benefit older adults psychologically (Silverstein, Cong and Li 20o6), and such a benefit is contingent on the personal resources (i.e. physical health and financial status) of the older adults (Chen and Liu 2012 ; Silverstein, Cong and Li 2007).

Rural China also has strict gender roles. If it is universally true that providing care in the family is a socially constructed expectation for women, it is more so in rural China than in urban China. A study on rural migrant women working in Beijing documented these women's common feelings of 'envy' of the 'happier and much more entertaining' life of urban women (Guo, Chow and Palinkas 2011). According to these women, before the migration, their lives were mainly confined in the family sphere and their self-identities were largely based on fulfilling various family obligations. The findings echo the differential vulnerability theory. Overall, rural China provides an interesting setting for studying issues relating to gender and family relations given the patrilineal nature of the society. The under-developed economy in rural China also provides perspectives to the issue that have been lacking in studies from developed countries.

\section{The present study}

In this study, we examined the possible effect of three types of intergenerational support (i.e. monetary, instrumental and emotional support) on levels of depression among Chinese rural elders, considering first the possible gender differences, and then the possible interactions between gender and marital status on such relationships. We distinguished the recent widowed from the long-term widowed in the analyses, given that the effect of support tends to vary by the recency of widowhood (Bankoff 1983). Our research questions are as follows: 
1. Do different forms of intergenerational support (i.e. monetary, instrumental and emotional support) affect fathers' and mothers' levels of depression differently?

2. Does parents' marital status (i.e. married, recently widowed or long-term widowed) affect the potential gendered relationship between intergenerational support and depression?

\section{Method}

\section{Participants}

This study used four-wave panel data from a longitudinal survey study conducted in rural Anhui province, China from 2001 to 2009. Located in eastern China, Anhui is a mostly rural and relatively under-developed province. It was ranked 26 th out of the $3^{1}$ provinces in China in terms of per capita Gross Domestic Product (National Statistics Bureau of China 2014). A stratified multi-stage sampling method was used to select the study population in the Chaohu region of Anhui province. The baseline study was conducted in 2001 with 1,802 potential respondents selected from the administrative records of 72 randomly selected villages within six rural townships in Chaohu. Surveys were conducted in respondents' homes. Functional health status, family relations and psychological wellbeing of the respondents were assessed. Interviews were structured so that the respondents discussed each child in turn, beginning with the eldest. Of the 1,802 individuals selected in 2001, 1,715 completed the survey (Wave 1), yielding a response rate of 95.3 per cent. In 2003, the first follow-up survey (Wave 2) was administrated to the 1,368 individuals who could be located and who agreed to participate $(79.8 \%$ of the original participants). In 2006, 1,o67 took part in the second follow-up survey (Wave 3 ). In 2009,808 out of these 1,067 participants participated in the third followup survey (Wave 4). Of the 907 participants who dropped out between follow-up studies, 649 (71.6\%) died, 174 (19.2\%) left their village and the rest either refused to participate or could not be located.

The present study is based on a sub data-set that pooled the information of all four waves of the survey. Respondents were included if they had answered the survey in two or more waves. To capture the changes in marital status over time, information from at least two waves is needed. Because the Wave 1 data provided information about a respondent's current marital status but not the recency of widowhood, data from the Wave 1 survey were not included in the analyses except for the information on marital status. We further excluded respondents with missing values on key study variables (i.e. marital status and depression), leading to a working 


\section{Man Guo et al.}

sample of 3,070 records from 1,327 parents. Compared to the respondents in the working sample, respondents who were not included in the analysis were significantly older, poorer, frailer and more depressed at the baseline. They were also more likely to be widowed, living alone and to receive instrumental support from children.

\section{Measures}

Depression. Depression was measured by nine questions based on the Center for Epidemiologic Studies - Depression scale (CES-D; Radloff 1997) and tailored to the target population (Silverstein, Cong and Li 2006). Among the nine items, three items indicated feelings of positive affect (happiness, enjoyment, pleasantness), two items indicated feelings of negative affect (lonely, upset), two items indicated a sense of marginalisation (useless, nothing to do) and two items indicated somatic symptoms (poor appetite, trouble sleeping). Respondents rated the frequency with which they had experienced each symptom in the past week $(o=$ rarely or none of the time, $1=$ some of the time, $2=$ most of the time). After coding the items in the same direction, we summed the nine variables, resulting in a depression scale ranging from o to 18 , with higher scores indicating greater depression. In the present study, Cronbach's alpha of this scale ranged from 0.77 and 0.80 across waves.

Intergenerational support. In the study, received support from adult children to parents included monetary, instrumental and emotional support. Received monetary support was indicated by the total amount of money that the parent had received from all children during the year prior to when the survey was carried out. Because the distribution of this variable was greatly skewed, we used the log of the Chinese Renminbi (RMB) currency value (plus one) of the total amount of money received to represent monetary support. We measured received instrumental support by the number of children (including their spouse) from whom older parents had received hands-on help with personal care or household chores during the past 12 months. We measured received emotional support by three questions that assessed the emotional cohesion of each parentchild dyad. The scale was adapted from the Intergenerational Solidarity Inventory (Mangen, Bengtson and Landry 1988). The three questions were 'Taking everything into consideration, how close do you feel to [this child]?' 'How much do you feel that [this child] would be willing to listen when you need to talk about your worries and problems?' and 'Overall, how well do you and [this child] get along together?' For each question, responses ranged from o to $2(\mathrm{o}=$ not at all, $1=$ somewhat, $2=$ very $)$. We 
computed an additive score for each child, ranging from o to 6 , and then took the average score across all children for each parent to represent this construct. Reliability of this scale ranged from $\alpha=0.94$ to 0.95 across waves.

Provided support to children included monetary and instrumental support. Because the downward monetary support was much less common and of a much smaller amount than the upward monetary support in the sample, a dummy variable was used to indicate whether older adults provided any monetary support to any children in the year prior to the survey $(1=$ yes, $o=n o)$. Provided instrumental support was assessed by another dummy variable indicating whether the older adult provided help with child care to any children in the family in the last year $(1=$ yes, $\mathrm{o}=$ no $)$.

Gender and marital status. Gender was measured as a dummy variable $(1=$ women $)$. Respondents were asked to indicate their marital status as either married or not married (most of the non-married were widowed) at each wave. We used the information from any two successive surveys to compute two dummy variables, recently widowed and long-term widowed, to indicate the marital status of a respondent at the latter survey point. Recently widowed was coded as 1 if the respondent had been married at the first survey but had become widowed by the time of the second survey. Longterm widowed was coded as 1 if the respondent reported being widowed at both surveys. The reference group was married, including respondents who were married at both surveys (i.e. continuously married) and the very few respondents $(\mathrm{N}=17)$ who had remarried after losing a spouse. For example, if an older adult was married at Wave 1 and became widowed at Wave 2 and continued to be so at Waves 3 and 4 , the marital status of this respondent was recently widowed for Wave 2 and long-term widowed for both Waves 3 and 4 .

Control variables. Control variables included socio-demographic characteristics of the older adults (age, income and health status) and living arrangement. Age was measured in years. Income was indicated by the total income that the respondent had received from work or pension in the past year. We used the natural $\log$ of the RMB currency value plus one $(\operatorname{Ln}(\mathrm{RMB}+1))$ to represent income. Health status was represented by functional health difficulties. Respondents indicated their level of difficulty $(o=$ no difficulties, $1=$ some difficulty, 2 = cannot do it without help) in performing ${ }_{15}$ tasks that represented activities of daily living (dressing or undressing, bathing, walking around the room, getting out of bed, standing up from a chair, going to the toilet, eating); instrumental activities of daily living (preparing meals, shopping, doing housework, taking the bus or train, managing 
money); and activities requiring physical strength, mobility and flexibility (lifting a ten-kilogram bag of rice; climbing one flight of stairs; walking 1 oo metres; and stooping, crouching or kneeling). The summed functional health difficulty scores ranged from o (no difficulties performing any task) to $3^{\circ}$ (unable to perform any task). Cronbach's alpha of this scale ranged from 0.90 to 0.94 across waves. Living arrangement was coded as a dummy variable $(\mathrm{o}=$ living alone, $1=$ living with children (including their spouse) and $2=$ living with someone else).

\section{Statistical analyses}

Our methodological approach was to use pooled time-series regression analysis in longitudinal studies (Johnson 1995). This technique incorporates both the cross-sectional effect of the independent variables on depression as well as the time-series effects within individuals. The data-set to be analysed was composed of three-wave panel data (2003, 2006 and 2009) with all the variables measured at each wave. Observations of each individual at each wave were represented by a separate record. Thus, one person could contribute up to three records to the data-set. The pooled time-series data structure allows the number of waves to vary among individuals, enabling researchers to include as many respondents as possible in the analysis.

Because the assumption of independence in ordinary least squares (OLS) regressions is violated in pooled time-series data, it is not appropriate to use OLS regressions for the analysis. As alternatives, either random or fixedeffects panel models can be used to estimate pooled time-series models (Allison 1994). Random effects models involve a generalised least square solution that allows time-invariant variables to be included in the equation. The model parameters are estimated using information of both withinand between-individual covariance in random effects models, making them more efficient than fixed-effects estimators (Allison 1994). But random effects models typically assume that time-invariant unobserved variables are uncorrelated with the variables in the model, which is a strong assumption often satisfied with experimental data only. Violation of this assumption may result in biased estimates in random effects models. In contrast, fixed-effects models allow time-invariant unobserved variables to be correlated with explanatory variables and provide a means for controlling for omitted variable bias. Their limitations are that, by focusing on withinperson variations only, they are usually less efficient, having larger standard errors, and normally resulting in loss of statistical power (Allison 1994; Hannan and Young 1977). A Hausman test was carried out to decide which model to use. The results $(p<0.001)$ indicated that fixed-effect models were more appropriate for this study. 
To compare older men and women in their psychological responses to intergenerational support and to investigate whether marital status affects such relationships, we ran two separate models for mothers and fathers. The equation of the basic fixed-effects model for the pooled time-series data-set with $i$ individuals and $t$ time periods was:

$$
\begin{aligned}
Y_{i t}= & u+b_{1} R W_{i t}+b_{2} L W_{i t}+b_{3} M S_{-} U P_{i t}+b_{4} I S_{-} U P_{i t}+b_{5} E S_{-} U P_{i t} \\
& +b_{6} M S \_D W_{i t}+b_{7} I S \_D W_{i t}+b_{j} Z_{j i t}+d_{i-1}+e_{i t},
\end{aligned}
$$

where $Y$ is the dependent variable (i.e. depression), $u$ is a constant and $b$ s are regression coefficients. Marital status is indicated by two dummy variables $\left(\mathrm{RW}_{i t}=\right.$ recently widowed, $\mathrm{LW}_{i t}=$ long-term widowed $)$. Support from children to parents included monetary, instrumental and emotional support $\left(\mathrm{MS}_{-} \mathrm{UP}_{i t}, \mathrm{IS}_{-} \mathrm{UP}_{i t}\right.$ and ES_UP $i t$, respectively), and support from parents to children included monetary $\left({\left.\mathrm{MS} \_D W_{i t}\right)}\right.$ and instrumental support $($ IS_DW $i t) . Z_{j i t}$ are $j$ time-varying control variables (age, living arrangement, income and functional health); $d_{i-1}$ is a set of $i-1$ respondent-specific dummy variables; and $e_{i t}$ is an error term, the residual from each withinperson regression of depression over time.

To answer the first research question - whether older men and women respond differently to various forms of intergenerational support - we tested the equation for men and women separately (Model 1 ) and used $z$ tests to compare the magnitude of the coefficients $b_{3}$ to $b_{7}$ in the samples of men and women (Paternoster et al. 1998). For instance, if women were more psychologically responsive to received monetary support, the magnitude of $b_{3}$ among women would be significantly larger than that among men. To answer the second question - whether marital status changes the potential gendered relationships between intergenerational support and depression we created a set of interactions between marital status and the intergenerational support that had significant main effects on depression and added them into the basic model (Model 2). Similarly, the equality of the coefficients of interactions among mothers and fathers was tested using $z$ tests. If the coefficient of an interaction term among mothers differed significantly from that coefficient among fathers, we would conclude that the effect of this type of support on mothers' and fathers' depression was further affected by marital status. All models were run in Stata using the xtset and xtreg procedure.

\section{Results}

Table 1 presents the sample characteristics. The 1,327 participants in the study were on average 72 years old in 2003 . About half $\left(5^{2} \%\right)$ of them 
T A в LE 1. Sample characteristics of Chinese older adults in Anhui, China in 2003, 2006 and 2009

\begin{tabular}{|c|c|c|c|}
\hline & 2003 & 2006 & 2009 \\
\hline $\mathrm{N}$ & 1,245 & 1,017 & 808 \\
\hline Mean age (SD) & $72.33(6.89)$ & $74.64(6.60)$ & $76.27(6.31)$ \\
\hline Women (\%) & $5^{2}$ & $5^{2}$ & $5^{1}$ \\
\hline \multicolumn{4}{|l|}{ Marital status (\%): } \\
\hline Married & $5^{6}$ & 53 & $5^{2}$ \\
\hline Recently widowed & 5 & 7 & 4 \\
\hline Long-term widowed & $3^{8}$ & $4^{\mathrm{O}}$ & 44 \\
\hline Mean income (SD) (¥) & $935.09\left(1,825.5^{1}\right)$ & $1,279 \cdot 97(2,343 \cdot 30)$ & $1,649 \cdot 79(4,145 \cdot 09)$ \\
\hline \multicolumn{4}{|l|}{ Living arrangement (\%): } \\
\hline Living alone & 21 & 21 & 26 \\
\hline Living with children & 49 & $5^{2}$ & 40 \\
\hline Living with someone else & 30 & 28 & 33 \\
\hline \multicolumn{4}{|l|}{$\begin{array}{l}\text { Intergenerational support } \\
\text { exchanges: }\end{array}$} \\
\hline $\begin{array}{l}\text { Mean received monetary } \\
\text { support (SD) (¥) }\end{array}$ & $943.7^{6}(988.90)$ & $1,243.10(1,354.76)$ & $1,610.87(1,911.31)$ \\
\hline $\begin{array}{l}\text { Received instrumental } \\
\text { support }(\%)\end{array}$ & $8_{5}$ & 77 & 67 \\
\hline $\begin{array}{l}\text { Providing monetary } \\
\text { support }(\%)\end{array}$ & $3^{8}$ & 15 & 23 \\
\hline Providing child care $(\%)$ & $4^{1}$ & 36 & 39 \\
\hline $\begin{array}{l}\text { Mean emotional } \\
\text { cohesion }(\mathrm{SD})(\mathrm{o}-6)\end{array}$ & $4.4^{2}(1.23)$ & $4.27\left(1.3^{1}\right)$ & $4.32(1.29)$ \\
\hline $\begin{array}{l}\text { Mean functional health } \\
\text { difficulties (SD) }\left(\mathrm{O}^{-} 3^{\mathrm{O}}\right)\end{array}$ & $5.40(7.22)$ & $6.87(7.61)$ & $5 \cdot 10(7 \cdot 49)$ \\
\hline $\begin{array}{l}\text { Mean depression (SD) } \\
\quad(0-18)\end{array}$ & $6.25(4.07)$ & $6.80(3.99)$ & $6.67(3.84)$ \\
\hline
\end{tabular}

Notes: $\mathrm{N}=1,327 . \mathrm{SD}$ : standard deviation.

were female and $5^{6}$ per cent were married in 2003. Over the eight-year period between 2001 and 2009, 167 older adults lost a spouse. Except for a steady increase in the amount of monetary support received by the respondents, there were no clear patterns of longitudinal changes across different types of intergenerational support. We speculate that such an increase may reflect the improved economic status of rural families in China. The income of the respondents also increased steadily over time. The mean CES-D score changed from 6.24 in 2003 , to 6.80 in 2006 and 6.67 in 2009 (out of a possible 18).

Table 2 presents the means, standard deviations, ranges and correlations of key study variables using the pooled data across all the waves $(\mathrm{N}=3, \mathrm{O} 7 \mathrm{O})$. The zero-order correlations showed that being a mother was associated with more monetary and instrumental support from children, a higher chance of providing child care, but a lower chance of providing monetary support to 
TA B LE 2. Correlations, means and standard deviations of key study variables in the pooled data

\begin{tabular}{|c|c|c|c|c|c|c|c|c|c|}
\hline & 1 & 2 & 3 & 4 & 5 & 6 & 7 & 8 & 9 \\
\hline 1. Women & 1.00 & $0.05^{* *}$ & $0.28 * *$ & $0.09^{*}$ & $0.12^{* *}$ & $-0.09^{* *}$ & $0.09 * *$ & 0.02 & $0.19^{* *}$ \\
\hline 2. Recently widowed & & 1.00 & $-0.20 * *$ & $0.04^{*}$ & 0.03 & -0.03 & -0.02 & -0.00 & $0.07^{*}$ \\
\hline 3. Long-term widowed & & & 1.00 & $0.08^{*}$ & $0.19^{* *}$ & $-0.20^{* *}$ & $-0.19^{* *}$ & $-0.05^{*}$ & $0.18^{* *}$ \\
\hline 4. Received monetary support $(\operatorname{Ln}(\mathrm{RMB}+1))$ & & & & 1.00 & $0.13^{* *}$ & $0.09 * *$ & $0.11 * *$ & $0.19 * *$ & $-0.16^{* *}$ \\
\hline 5. Received instrumental support & & & & & 1.00 & -0.03 & $-0.04^{*}$ & $0.10^{* *}$ & $0.09 *$ \\
\hline 6. Providing monetary support & & & & & & 1.00 & $0.3^{* *}$ & $0.14^{* *}$ & $-0.22^{* *}$ \\
\hline 7. Providing child care & & & & & & & 1.00 & $0.06^{* *}$ & $-0.19^{* *}$ \\
\hline 8. Emotional cohesion & & & & & & & & 1.00 & $-0.31 * *$ \\
\hline 9. Depression & & & & & & & & & 1.00 \\
\hline Mean & $0.5^{2}$ & 0.06 & 0.40 & 6.37 & 0.77 & 0.26 & 0.39 & $4 \cdot 34$ & 6.54 \\
\hline Standard deviation & $0.5^{\circ}$ & 0.23 & 0.49 & 1.68 & 1.27 & 0.44 & 0.45 & 1.27 & 3.99 \\
\hline Minimum & $\mathrm{o}$ & o & o & o & o & o & o & o & o \\
\hline Maximum & 1 & 1 & 1 & 9.81 & 9.00 & 1 & 1 & 6.00 & 18.00 \\
\hline
\end{tabular}

Notes: $\mathrm{N}=3,070$. RMB: Renminbi.

Significance levels: $* p<0.05, * * p<0.01$ (two-tailed test). 


\section{Man Guo et al.}

children. Gender of the parents was not related to the emotional cohesion with children. Both the recent and the long-term widowhood were associated with more monetary support from children. But only the long-term widowhood was associated with more instrumental support from children, less close relationships with them, and a lower chance of providing either monetary or instrumental support. Regarding the relationship between support exchanges and depression, providing and receiving monetary support, providing child care and having closer relationships with children were all associated with lower levels of depression. However, receiving instrumental support was related to parents' higher level of depression.

To address the first research question, the first fixed-effects models estimated the effect of various intergenerational support on mothers' and fathers' level of depression, respectively, while controlling for basic sociodemographic factors (Table 3 ). Model 1 provides some evidence for the psychological benefit of receiving support among Chinese rural elders, but such a benefit was limited to monetary and emotional support only. Receiving instrumental support from children was not predictive of parents' level of depression. Significance tests further revealed that the psychological benefits of receiving monetary support were comparable for mothers $(b=-0.33)$ and fathers $(b=-0.14, Z=1.81, p>0.05)$, but having a closer relationship with children was significantly more beneficial for mothers $(b=-0.79)$ than for fathers $(b=-0.49, Z=2.37, p<0.05)$. Examining the influence of providing intergenerational support on Chinese rural elderly, we found that providing monetary support had a similarly positive effect on the psychological wellbeing of mothers $\left(b=-0.5^{8}\right)$ and fathers $\left(b=-0.4^{6}\right.$, $Z=0.33, p>0.05)$. Providing child care was not associated with levels of depression, regardless of parents' gender.

Other significant predictors of depression in Model 1 included marital status, age, living arrangement and functional status. Recent widowhood, not long-term widowhood, was predictive of a higher level of depression among fathers only. Living with children was only protective of mothers' psychological wellbeing. Older age and more functional health difficulties were both associated with higher levels of depression in both men and women.

Our second research question asked whether parents' marital status affects any gendered relationships between intergenerational support and depression. To address this question, we added interactions between marital status (recently widowed and long-term widowed versus married) and the three forms of support that had significant main effects on depression (i.e. received monetary support, providing monetary support and emotional cohesion) in the analyses (Model 2). Table 3 shows that two out of the six interaction terms were significant. First, 'Received monetary support $\times$ Recently widowed' was significant in the fathers' sample $\left(b=0.5^{6}\right)$. This 
T А в L E 3. Unstandardised regression estimates for pooled time-series fixed-effects model predicting levels of depression among rural Chinese elderly

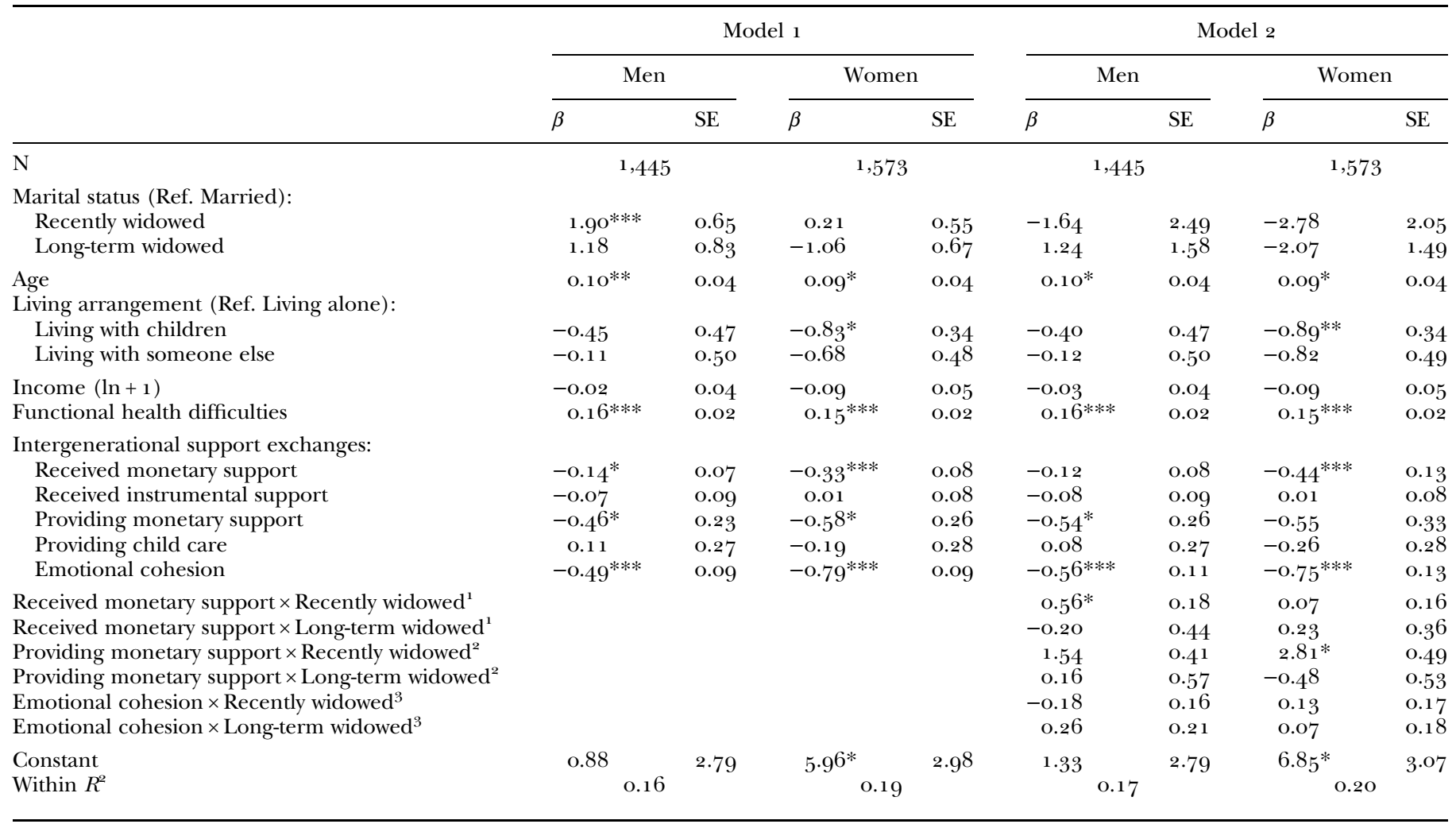

Notes: $\mathrm{N}=3, \mathrm{o} 7 \mathrm{o}$. SE: standard error. Ref.: reference group. 1. Ref.: received monetary support $\times$ married. 2. Ref.: providing monetary support $\times$ married. 3. Ref.: emotional cohesion $\times$ married.

Significance levels: $* p<0.05, * * p<0.01, * * * p<0.001$. 


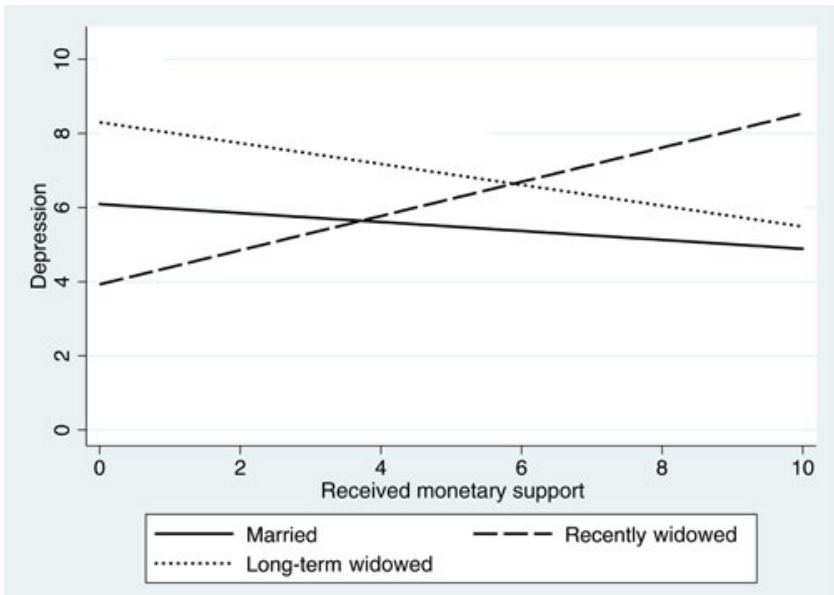

Figure 1. Estimated relationship between received monetary support and level of depression among fathers, stratified by marital status.

Note: $\mathrm{N}=1,474$.

means that compared to married fathers, recently widowed fathers would be more depressed if they received more monetary support from children. The finding was not generalisable to long-term widowers or mothers, and such a gender difference was significant $(b=0.07$ for the interaction among mothers, $Z=1.98, p<0.05)$. Figure 1 illustrates such marital status differences in the relationship between received monetary support and level of depression among fathers.

Second, 'Providing monetary support $\times$ Recently widowed' was significant in the mothers' sample only $(b=2.81)$. The findings means that the psychological benefit of providing monetary support to children not only disappeared among newly widowed mothers, doing so was actually related to their higher level of depression. Figure 2 illustrates such a relationship. This finding did not hold true for long-term widows or fathers and the gender difference was significant $(b=1.54$ for the interaction among fathers, $Z=2.00$, $p<0.05)$. Finally, the interactions between marital status and emotional cohesion were not significant in either sample, suggesting that, regardless of gender, emotional supports from children were not more psychologically protective for Chinese rural elderly when they experience widowhood.

\section{Discussion}

The purpose of this study was twofold: (a) to compare the potential effect of three forms of intergenerational support on levels of depression among 


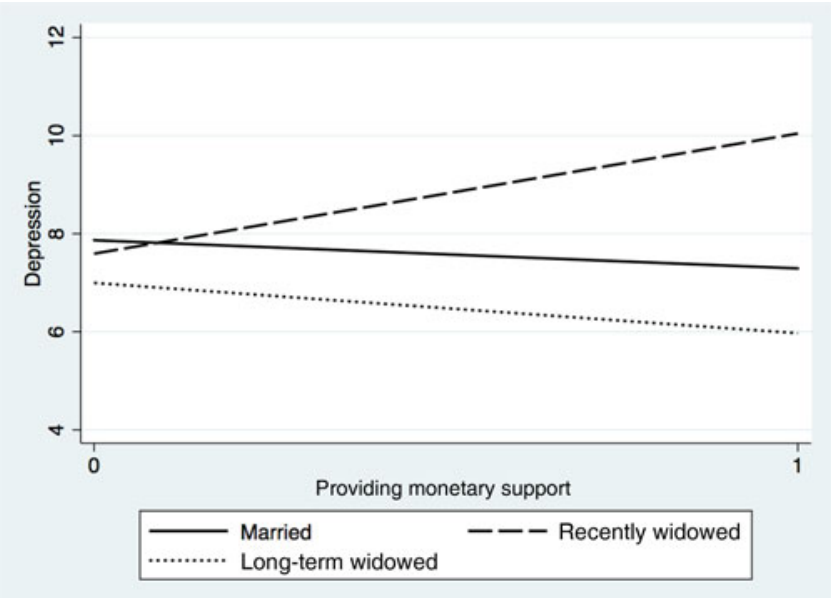

Figure 2. Estimated relationship between whether providing monetary support $(1=$ yes, $\mathrm{O}=$ no $)$ and level of depression among mothers, stratified by marital status.

Note: $\mathrm{N}=1,596$.

older men and women, and (b) to assess whether any gendered patterns in the relationships between support and depression are affected by parents' marital status. The findings of this study offer partial support to differential vulnerability theory, showing that such differential vulnerability only holds true for certain types of support. As expected, we found that a closer relationship with children was associated with lower levels of depression among both mothers and fathers, but such an effect was significantly stronger for mothers. In other words, mothers benefited more than fathers psychologically from closer parent-child relationships. Both receiving and providing monetary support had a comparable beneficial effect on mothers and fathers, whereas exchanges in instrumental support with children were not predictive of parents' level of depression.

The finding that mothers were more psychologically responsive to emotional relationships is consistent with the findings in several studies conducted both in the United States and China (Cheng and Chan 2oo6; Fiori and Denckla 2012). Such a finding points to the importance of kinprovided emotional support for women. It also lends support to the idea that women's social relationships put more emphasis on the emotional aspects, that is, more on intimacy and nurturance than on instrumental support behaviours (Fiori and Denckla 2012). Such a gendered reactivity to social relationships has its origin in the larger social context in which men and women have different social roles and coping resources (McDonough and Walters 2001). In rural China, families are characterised 


\section{Man Guo et al.}

by strong gender roles and the sense of tight kin networks (Zhang et al. 2004). As the lives of Chinese rural women are more confined to a limited arena of social relations/activities than their male counterparts, they tend to have more frequent interactions and support exchanges with their adult children, and such relationships may be particularly important for their sense of worth, self-identify and meaning of life. Having close relationships with children thus helps to confirm their sense of mattering and bolster the feelings that they are cared for, having a more beneficial effect on women's psychological wellbeing than on their male counterparts. Such bond, care and comfort from primary family members like offspring are believed to be most effective in protecting individual wellbeing (Thoits 2011).

In terms of monetary support, different from the differential vulnerability theory, we found that receiving and providing monetary support benefited mothers and fathers to a similar extent. We speculate that this may be because the sample was from a relatively poor rural region with low pension coverage. Economic security provided by adult children thus is essential for both older men and women by reducing their psychological stress related to financial hardship. Such support may also convey that the adult children cared for the parents, enhancing their sense of mattering and self-esteem (Thoits 2011). It is necessary to replicate this study with samples from more developed areas in China or with national probability samples of Chinese elders. In addition, the results may also be attributive to the fact that most of the monetary support provided by adult children to their ageing parents is towards the older couple as a family, not an individual parent. This means that monetary support received by mothers might benefit fathers as well, and vice versa. Such a 'spillover' effect may obscure the potential gender differences in their responses to receiving the support from children. More nuanced measurements such as assessing the monetary value of gifts given to fathers and mothers individually shall be used in future studies to examine the gender similarity/differences in such relationships better.

Despite the disadvantaged economic conditions of the older adults in this study, both men and women benefited from providing monetary support to children. The finding emphasises the importance of reciprocity in family relations, even among individuals who have limited resources for exchanges. When the flow of support is highly unequal in dyadic relationships, the results may be demoralisation and depression (Kawachi and Berkman 2001). It is also worth mentioning that the assessment of monetary support in this study included presence of gifts and the downward monetary support was measured by a yes-or-no question. It is reasonable to assume that a simple gesture of giving, either through a little gift or a small 
amount of financial help to their adult children, is likely to create a sense of self-fulfillment and self-worth among rural elderly, benefiting their psychological wellbeing. Together, the findings of women being more psychologically responsive to emotional support than men but not more so to financial support exchanges echo the idea that women's social relationships are more emotionally oriented than men's.

In this study, neither providing nor receiving instrumental support was related to depression in both mothers and fathers. Lack of psychological benefit of receiving instrumental support in this study may be related to the relatively good health status of the respondents, who on average had low functional limitation scores (mean ranged from 5.10 to 6.88 , out of 30 , across the waves). For a support to be efficacious, the types of support received must match the demands of the individual's stressful situation (Cohen and Wills 1985). While deteriorating functional health of older adults often attracts more hands-on help, instrumental support provided to older adults who are still in good health may lead to a sense of dependency, possibly impairing their psychological wellbeing (Keyes and Ryff 1998). This may partly explain why the receipt of instrumental support was inconsequential for both fathers' and mothers' levels of depression. Providing child care was not associated with parents' depression either. It is likely that, because it is quite common and expected in rural China (in this study, about $40 \%$ of the respondents provided such help across the waves), providing child care may not result in the feelings of fulfilment among the older adults. This finding may reflect that certain family relationships, such as child care in rural China, are generally considered obligatory (Antonucci and Akiyama 1995). As such, adult children who receive such care may not be particularly expressive of their appreciation, thereby not boosting feelings of self-worth and efficacy in the older parents.

We also investigated the possible joint effects of gender and marital status on the relationships between intergenerational support and parental wellbeing. We found mothers' greater psychological response to emotional support was not further confounded by marital status. Being widowed, either for a relatively short period of time or for a long time, did not make rural Chinese elders benefit more psychologically from emotional support from children. This finding demonstrates the universal importance of close parent-child relationships in maintaining the psychological wellbeing of rural Chinese elders across marital status.

What is surprising is that recently widowed fathers had a higher level of depression than married fathers if they received more monetary support from children. Such a counter-intuitive finding may be explained by the 'optimal fit' framework of providing and receiving support (Cohen and Wills 1985; Coyne, Wortman and Lehman 1988). Cohen and Wills 


\section{Man Guo et al.}

$(1985)$ noted that for the buffering effect of support to be realised, there must be a good match between the coping requirement and the type of support provided. Although Chinese widows may be likely to rely on adult children as their sole source of income when their spouses die, the financial stability of Chinese widowers is usually less affected by spousal death ( $\mathrm{Li}$ et al. 2005). However, spousal loss seemed to trigger more monetary support from children among both widowers and widows in this study (we re-ran the correlations in Table 2 for mothers and fathers separately, and the positive relationship between recent widowhood and received monetary support remained the same for both samples). It is possible that the receipt of excessive monetary support from children resulted in widowed fathers feeling a sense of dependency and role reversal with their adult children, eroding their autonomy, and consequently impairing their wellbeing. The finding of diminishing benefits with increasing support has been reported elsewhere and has been found to be more significant among older men than older women and among unmarried elders than married elders (Matire et al. 2002; Penning and Strain 1994; Silverstein, Chen and Heller 1996). Such a pattern might be particularly true in our rural sample, given the strong social norms in traditional Chinese culture that men are expected to be self-sufficient through work (Li et al. 2005). Older fathers in this study may be socialised to express traditionally masculine roles such as providing for the families, and they may feel that their masculinity is threatened when receiving more monetary support from children upon widowhood. In contrast, the psychological benefit of receiving such support remained the same among mothers regardless of their marital status or their phase of conjugal bereavement.

Although providing monetary support was shown to benefit both mothers and fathers psychologically in this study, doing so was actually related to a higher level of depression among newly widowed mothers. As stated earlier, financial difficulty is the major stressor among widowed women (Sonnenberg et al. 200o). It may hit Chinese rural women particularly hard as the farm work performed by the lost husbands might be the major source of income for the family. When facing such a major adversity, participating in social network and providing support may be more harmful than helpful for women with low resources (Kawachi and Berkman 2001). A study on black elderly similarly reported that older adults who had fewer resources were more psychologically vulnerable to social relationships when experiencing stressful events (Husaini et al. 1991). Upon widowhood, the expected flow of monetary support would be from children to bereaved mothers. Downward support is not only at odds with the expected family relations, it may also create feelings of being unworthy and uncared for among the mothers, consequently hurting their psychological wellbeing. 
In contrast, as widowhood tends to have a weaker financial impact on fathers than on mothers, providing monetary support to children was not found to be related to worse psychological wellbeing among newly widowed men.

It is worth noting that the diminishing benefits of either receiving or providing monetary support were only found among newly widowed parents. We did not find any detrimental effect of receiving/providing monetary support among fathers/mothers in the stage of late bereavement. Jacobson (1986) pointed out the importance of timing in studying the effect of support. The same support may result in different consequences as one moves through various life stages and as one carries out continuous appraisal and reappraisal of their support demand and support received. For parents experiencing widowhood, the timing of support is linked with the process of coping and coping stages (Bankoff 1983). Recently widowed parents may be particularly sensitive to intergenerational support because at this stage they typically withdraw psychologically from social relationships and avoid looking forward to the reorganisation of their lives (Bankoff 1983; Bowlby 1982). Monetary assistance from children, no matter how well meaning and supportive it is intended, may be inconsequential or even detrimental to widowed fathers in their early bereavement. Similarly, even providing monetary support to offspring helps to fulfil mothers' family responsibilities, but doing so may be psychologically taxing on mothers during the most vulnerable time of early bereavement. It is reasonable to assume that as bereaved parents begin to resume normal life and rebuild their social relationships, and as the demand for support exchanges escalates, the benefit of intergenerational support would reappear.

Some limitations of this study are worth mentioning. First, we compared marital status at different waves to assess the recency of widowhood. As the surveys were three years apart, it was possible that a 'recently widowed' person had been in this status for nearly three years. Without knowing exactly when the death of a spouse occurred, our results may not be able to capture fully older adults' experience at the most intensive bereavement stages. Studies of larger sample sizes may be able to include more older adults at the early bereavement stage and to depict more accurately the support changes upon widowhood and their impact on older adults. Similarly, the assessment of the timing of support was quite general, reflecting the patterns that occurred in the past year. Such measurements could not capture fully the immediate changes in support demand and support provision upon loss of a spouse. Retrospective questions addressing the support exchanges right before and after widowhood would be the most helpful information to address the research questions. Third, our scale of 


\section{Man Guo et al.}

emotional support included items reflecting perceived relationship quality rather than received support. Although the scale items had adequate reliability, it remains untested whether using direct measures of emotional supportive behaviours would result in the same findings. In addition, as we mentioned earlier, we used the average emotional cohesion score to represent this construct. This may have obscured potential gender or marital status differences in other aspects of the parent-child relationship, such as the closest relationship qualities between the parent and one particular child. It is important to evaluate rigorously these potentially important intervening constructs to arrive at a better understanding of the dynamic experience of receiving intergenerational support among older parents. Lastly, the measurement of instrumental support from older adults to their adult children was limited to child care only, a form of very specific instrumental support that may not be need-driven. More comprehensive assessment of other types of downward instrumental support, such as help with household chores or personal care, might yield different findings.

Despite these limitations, this study is the first one that we are aware of investigating the possible joint effects of gender and marital status in the relationship between intergenerational support and parental wellbeing. As shown, simultaneously analysing gender and marital status provides perspectives that are not available in studies only considering one factor. Moreover, whereas most previous studies have focused on one type of support, we examined the multiple types of support, both upward and downward, in the same models and revealed the relative importance of children's monetary and emotional support compared to instrumental support. Our results also revealed the influence of recent widowhood on the monetary support exchanges among fathers and mothers. Lastly, most documented gender-patterned familial support and parental wellbeing have been based on Western studies. Using a sample from rural China that has vastly different social and economic structures, we identified different patterns of intergenerational support and their influence on later-life wellbeing based on gender and marital status. These findings provide an evaluation of the external validity of research conducted in Western developed nations and contributes to theoretical refinements.

\section{Conclusions}

It is generally assumed that intergenerational support has a beneficial effect on the psychological wellbeing of older parents, particularly of older mothers. Our findings provide some evidence for this assumption and 
show that mothers' greater reactivity to intergenerational support is specific to emotional support only. The findings of this study also show that whether intergenerational support is helpful, inconsequential or detrimental to parents' psychological wellbeing is dependent upon the marital status of the parent and the bereavement process of widowed parents. In this study, receiving more monetary support from children was related to worse psychological outcomes among newly widowed fathers and providing monetary support to children was related to worse psychological outcomes among newly widowed mothers. We explained these findings in the context of strong social norms governing different types of familial relationships in Chinese culture. Although with imperfect measurement, we also emphasised the temporal dimension of family support for understanding the support process and its influence on older parents. We argued that the gender and marital status patterns observed in this study are attributed to more fundamental differences in men's and women's positions in the Chinese society, and the differences in men's and women's social and psychological resources and needs.

The findings point to the importance of disaggregating measures of different types of support in order to discern gender and marital status differences in family support and their influences on older parents. The findings also show that it is critical to understand the timing of the support received and the 'optimal-fit' between support demand and support provision in evaluating the consequences of intergenerational support on older adults. Older parents represent a very diverse group, differing in their resources, needs and preferred ways of family interaction. All these factors are continuously reshaped by ongoing modernisation, urbanisation and globalisation. In the context of China, given the sharp decrease in the fertility rate, future cohorts of older people will have far fewer children to turn to for support. It will be important to monitor the consequences of these social changes on older Chinese people - particularly women, who have traditionally depended heavily on children as their main source of support and who are more likely to be affected by parent-child relationships.

\section{Acknowledgements}

This research was supported by grants from the Fogarty International Center of the National Institutes of Health (Ro3TWo106o-o1) and the USC US-China Institute. The authors would like to thank Shuzhuo Li for his leadership as the Co-director of the larger research project on Chinese rural elders and Dongmei Zuo for her contribution to data collection. Human subject research approval was obtained from the University of Southern California Institutional Review Board. 


\section{References}

Agree, E. M., Biddlecom, A. E., Chang, M.-C. and Perez, A. E. 2002. Transfers from older parents to their adult children in Taiwan and the Philippines. Journal of Crosscultural Gerontology, 1 7, 4, 269-94.

Allison, P. D. 1994. Using panel data to estimate the effects of events. Sociological Methods and Research, 23, 2, 174-99.

Antonucci, T. C. and Akiyama, H. 1987. An examination of sex differences in social support among older men and women. Sex Roles, 17, $11 / 12,737-49$.

Antonucci, T. C. and Akiyama, H. 1995. Convoys of social relations: family and friendships within a life span context. In Blieszner, R. and Bedford, V. H. (eds), Handbook of Aging and the Family. Greenwood, Westport, Connecticut, 355-71.

Bankoff, E. A. 1983. Social support and adaptation to widowhood. Journal of Marriage and Family, 45, 4, 827-39.

Bowlby, J. 1982. Attachment and loss: retrospect and prospect. American Journal of Orthopsychiatry, 52, 4, 664-78.

Brown, S. L., Nesse, R. M., Vinokur, A. D. and Smith, D. M. 2003. Providing social support may be more beneficial than receiving it: results from a prospective study of mortality. Psychological Science, 14, 4, 320-7.

Carr, D., House, J. S., Wortman, C., Nesse, R. and Kessler, R. C. 2001. Psychological adjustment to sudden and anticipated spousal loss among older widowed persons. Journals of Gerontology: Psychological Sciences and Social Sciences, 56B, 4, 237-48.

Carr, D. and Utz, R. 2004. Late-life widowhood in the United States: new directions in research and theory. In Davidson, K. and Fennel, G. (eds), Intimacy in Later Life. Transaction, New Brunswick, New Jersey, 19-46.

Chen, F. and Liu, G. 2012. The health implications of grandparents caring for grandchildren in China. Journals of Gerontology: Psychological Sciences and Social Sciences, $\mathbf{6}_{7} \mathbf{B}, 1,99-112$.

Cheng, S. T. and Chan, A. C. M. 2006. Relationship with others and life satisfaction in later life: do gender and widowhood make a difference? Journals of Gerontology: Psychological Sciences and Social Sciences, 61B, 1, 46-53.

China Research Center on Ageing 20og. Data Analysis of the Sampling of Survey of the Aged Population in China. China Standard, Beijing.

Chou, R.J.A. 2011 . Filial piety by contract? The emergence, implementation, and implications of the 'family support agreement' in China. The Gerontologist, 51, 1, $3-16$.

Cohen, S. and Wills, T. A. 1985 . Stress, social support, and the buffering hypothesis. Psychological Bulletin, 98, 2, 310-57.

Cong, Z. and Silverstein, M. 201 1. Grandparenting in rural China. In Mehta, K. K. and Thang, L. L. (eds), Experiencing Grandparenthood: An Asian Perspective. Springer, New York, 109-27.

Connidis, I. A. and Davis, L. 1992. Confidants and companions: choices in later life. Journals of Gerontology: Social Sciences, 47, 3, $115^{-22 .}$

Coyne, J. C., Wortman, C. B. and Lehman, D. R. 1988. The other side of support: emotional overinvolvement and miscarried helping. In Gottlieb, B. H. (ed.), Marshaling Social Support: Formats, Processes, and Effects. Sage, Newbury Park, California, 305-30.

Cyranowski, J. M., Frank, E., Young, E. and Shear, M. K. 200o. Adolescent onset of the gender difference in lifetime rates of major depression: a theoretical model. Archives of General Psychiatry, 57, 1, 21-7.

Delbès, C. and Gaymu, J. 2002. The shock of widowhood on the eve of old age: male and female experiences. Population English Edition, 57, 6, 885-914. 
Eggebeen, D. J. 1992. Family structure and intergenerational exchanges. Research on Aging, 14, 4, 427-47.

Elliott, M. 2001. Gender differences in causes of depression. Women $\mathcal{E}$ Health, 33, 3, $183-98$.

Fiori, K. L. and Denckla, C. A. 2012. Social support and mental health in middleaged men and women: a multidimensional approach. Journal of Aging and Health, 24, 3, 407-38.

Friedman, J., Knodel, J., Cuong, B. T. and Anh, T. S. 2003. Gender dimensions of support for elderly in Vietnam. Research on Aging, 25, 6, 587-63o.

Furstenberg, F. F., Hoffman, S. D. and Shrestha, L. 1995. The effect of divorce on intergenerational transfers: new evidence. Demography, 32, 3, 319-33.

$\mathrm{Gu}$, S. and Liang, J. 2000. China: population aging and old age support. In Bengtson, V. L., Kim, K., Myers, G. and Eun, K. (eds), Aging in East and West: Families, States, and the Elderly. Springer, New York, 59-94.

Guo, M., Chow, N. W. S. and Palinkas, L. A. 2011 . Circular migration and life course of female domestic workers in Beijing. Asian Population Studies, 7, 1, 51-67.

Ha, J. H., Carr, D., Utz, R. L. and Nesse, R. 2006. Older adults' perceptions of intergenerational support after widowhood: how do men and women differ? Journal of Family Issues, 27, 1, 3-30.

Haines, V. A., Beggs, J. J. and Hurlbert, J. S. 2008. Contextualizing health outcomes: do effects of network structure differ for women and men? Sex Roles, 59, 3, $164-75$.

Hann, D., Baker, F., Denniston, M., Gesme, D., Reding, D., Flynn, T., Kennedy, J. and Kieltyka, R. L. 2002. The influence of social support on depressive symptoms in cancer patients: age and gender differences. Journal of Psychosomatic Research, 52, 5 , 279-83.

Hannan, M. T. and Young, A. A. 1977. Estimation in panel models: Results on pooling cross-sections and time series. In Leinhardt (Ed.), Sociological Methodology. Jossey-Bass, San Francisco, 52-83.

Husaini, B. A., Moore, S. T., Castor, R. S., Neser, W., Griffin, D., Linn, J. G. and Whitten-Stovall, R. 1991. Social density, stressors, and depression: gender differences among the black elderly. Journal of Gerontology, 46, 5, 236-42.

Ingersoll-Dayton, B., Neal, M. B. and Hammer, L. B. 2001. Aging parents helping adult children: the experience of the sandwiched generation. Family Relations, 5o, 3, 262-71.

Jacobson, D. E. 1986. Types and timing of social support. Journal of Health and Social Behavior, 27, 3, 250-64.

Janzen, B. L. 1998. Women, Gender and Health: A Review of the Recent Literature. 2. Available online at http://www.pwhce.ca/pdf/janzen.pdf [Accessed 3o November 2015].

Johnson, D. R. 1995. Alternative methods for the quantitative analysis of panel data in family research: pooled time-series models. Journal of Marriage and Family, 57, 4, $1065^{-77}$.

Kalmijn, M. 2007. Gender differences in the effects of divorce, widowhood and remarriage on intergenerational support: does marriage protect fathers? Social Forces, 85, 3, 1079-104.

Kawachi, I. and Berkman, L. F. 2001. Social ties and mental health. Journal of Urban Health, 78, 3, 45 $8-67$.

Keyes, C. L. M. and Ryff, C. D. 1998. Generativity in adult lives: social structural contours and quality of life consequences. In McAdams, D. P. and de St Aubin, E. (eds), Generativity and Adult Development. American Psychological Association, Washington DC, 227-63.

Lee, G. R., DeMaris, A., Bavin, S. and Sullivan, R. 2001. Gender differences in the depressive effect of widowhood in later life. Journals of Gerontology: Psychological Sciences and Social Sciences, 56B, 1, 56-61. 


\section{Man Guo et al.}

Li, L., Liang, J., Toler, A. and Gu, S. 2005. Widowhood and depressive symptoms among older Chinese: do gender and source of support make a difference? Social Science Eं Medicine, 6o, 3, 637-47.

Mangen, D., Bengtson, V.L. and Landry, P. H., Jr (eds) 1988. The Measurement of Intergenerational Relations. Sage, Beverly Hills, California.

Matire, L. M., Stephens, M. A. P., Druley, J. A. and Wojno, W. C. 2002. Negative reactions to received spousal care: predictors and consequences of miscarried support. Health Psychology, 21, 2, 167-76.

McDonough, P. and Walters, V. 2001. Gender and health: reassessing patterns and explanations. Social Science E Medicine, 52, 4, 547-59.

National Statistics Bureau of China 2014. China Statistical Yearbook 2014. Statistics Press, Beijing.

Ofstedal, M. B., Reidy, E. and Knodel, J. 2004. Gender differences in economic support and well-being of older Asians. Journal of Cross-cultural Gerontology, 19, 3, $165^{-201 .}$

Paternoster, R., Brame, R., Mazerolle, P. and Piquero, A. 1998. Using the correct statistical test for the equality of regression coefficients. Criminology, $\mathbf{3 6}, 4,859-66$.

Pei, X. and Pillai, V. K. 1999. Old age support in China: the role of the state and the family. International Journal of Aging and Human Development, 49, 3, 197-212.

Penning, M. J. and Strain, L. A. 1994. Gender differences in disability, assistance, and subjective well-being in later life. Journal of Gerontology, 49, 4, 202-8.

Radloff, L. 1997. The CES-D scale: a self-report depression scale for research in the general population. Applied Psychological Measurement, 1, 3, 385-401.

Reevy, G. M. and Maslach, C. 2001. Use of social support: gender and personality differences. Sex Roles, 44, 7/8, 437-59.

Rieker, P. P. and Bird, C. E. 200o. Sociological explanations of gender differences in mental and physical health. In Bird, C. E., Conrad, P. and Fremont, A. M. (eds), Handbook of Medical Sociology. Prentice Hall, Upper Saddle River, New Jersey, 98-1 13 .

Roan, C. L. and Raley, R. K. 1996. Intergenerational coresidence and contact: a longitudinal analysis of adult children's response to their mother's widowhood. Journal of Marriage and the Family, 58, 3, 708-1 7.

Robb, C., Small, B. and Haley, W. E. 2008. Gender differences in coping with functional disability in older married couples: the role of personality and social resources. Aging and Mental Health, 12, 4, 423-33.

Rosenfield, S. 1989. The effects of women's employment: personal control and sex differences in mental health. Journal of Health and Social Behavior, 3o, 1, 77-91.

Shumaker, S. A. and Hill, D. R. 1991. Gender differences in social support and physical health. Health Psychology, 10, 2, 102-1 1.

Shye, D., Mullooly, J. P., Freeborn, D. K. and Pope, C. R. 1995. Gender differences in the relationship between social network support and mortality: a longitudinal study of an elderly cohort. Social Science Ev Medicine, 41, 7, 935-47.

Silverstein, M., Chen, X. and Heller, K. 1996. Too much of a good thing? Intergenerational social support and the psychological well-being of older parents. Journal of Marriage and Family, 58, 4, 970-82.

Silverstein, M., Cong, Z. and Li, S. 20o6. Intergenerational transfer and living arrangements of older people in rural China: consequences for psychological well-being. Journals of Gerontology: Psychological Sciences and Social Sciences, 61 B, 5, $5^{2} 5^{6-66 .}$

Silverstein, M., Cong, Z. and Li, S. 2007. Grandparents who care for their grandchildren in rural China: benefactors and beneficiaries. In Powell, J. L. and Cook, I. G. (eds), New Perspectives on China and Aging. Nova Publishers, New York, 49-72. 
Silverstein, M., Conroy, S.J., Wang, H., Giarrusso, R. and Bengtson, V. L. 2002. Reciprocity in parent-child relations over the adult life course. Journals of Gerontology: Psychological Sciences and Social Sciences, $\mathbf{5 7}_{\mathbf{B}} \mathbf{B}, \mathbf{1}, 3^{-1} 3$.

Silverstein, M., Gans, D. and Yang, F. M. 2006. Intergenerational support to aging parents: the role of norms and needs. Journal of Family Issues, 27, 8, 1068-84.

Sobieszczyk, T., Knodel, J. and Chayovan, N. 2003. Gender and wellbeing among older people: evidence from Thailand. Ageing $\mathcal{E}$ Society, 23, 6, 701-35.

Sonnenberg, C. M., Beekman, A. T. F., Deeg, D. J. H. and Tilburg, W. 20oo. Sex differences in late-life depression. Acta Psychiatrica Scandinavica, 101, 4, 286-92.

Sonnenberg, C. M., Deeg, D.J. H., Van Tilburg, T. G., Vink, D., Stek, M. L. and Beekman, A. T.F. 2013. Gender differences in the relation between depression and social support in later life. International Psychogeriatrics, 25, 1, 61-70.

Stroebe, M., Stroebe, W. and Schut, H. 2001. Gender differences in adjustment to bereavement: an empirical and theoretical review. Review of General Psychology, 5, $1,62-83$.

Stroebe, W. and Stroebe, M. S. 1987. Bereavement and Health: The Psychological and Physical Consequences of Partner Loss. Cambridge University Press, Cambridge.

Takizawa, T., Kondo, T., Sakihara, S., Ariizumi, M., Watanabe, N. and Oyama, H. 2006. Stress buffering effects of social support on depressive symptoms in middle age: reciprocity and community mental health. Psychiatry and Clinical Neuroscience, 6o, 6, $65^{2}-61$.

Thoits, P. A. 2011 . Mechanisms linking social ties and support to physical and mental health. Journal of Health and Social Behavior, 52, 2, 145-61.

Turner, R.J. and Marino, F. 1994. Social support and social structure: a descriptive epidemiology. Journal of Health and Social Behavior, 35, 3, 193-212.

Uchino, B. N., Cacioppo, J. T. and Kiecolt-Glaser, J. K. 1996. The relationship between social support and physiological processes: a review with emphasis on underlying mechanisms and implications for health. Psychological Bulletin, 119, 3, $488-531$.

Umberson, D., Chen, M. D., House, J. S., Hopkins, K. and Slaten, E. 1996. The effect of social relationships on psychological well-being: are men and women really so different? American Sociological Review, 61, 5, 837-57.

Umberson, D., Wortman, C. B. and Kessler, R. C. 1992. Widowhood and depression: explaining long-term gender differences in vulnerability. Journal of Health and Social Behavior, 33, 1, 10-24.

Utz, R. L., Reidy, E. B., Carr, D., Nesse, R. and Wortman, C. 2004. The daily consequences of widowhood: the role of gender and intergenerational transfers on subsequent housework performance. Journal of Family Issues, 25, 5, 683-71 2.

van Daalen, G., Sanders, K. and Willemsen, T. M. 2005. Sources of social support as predictors of health, psychological well-being and life satisfaction among Dutch male and female dual-earners. Women $\mathcal{E}^{\circ}$ Health, 41, 2, 43-62.

Van den Hoonaard, D. K. 2001. The Widowed Self: The Older Woman's Journey Through Widowhood. Wilfrid Laurier University Press, Waterloo, Canada.

Van Grootheest, D. S., Beekman, A. T. F., Broese van Groenou, M. I. and Deeg, D. J. H. 1999. Sex differences in depression after widowhood. Do men suffer more? Social Psychiatry and Psychiatric Epidemiology, 34, 7, 391-8.

Williams, C. L. 1993. Psychoanalytic theory and the sociology of gender. In England, P. (ed.), Theory on Gender/Feminism on Theory. Aldine de Gruyter, New York, 131-49.

$\mathrm{Wu}, \mathrm{X}$. and DeMaris, A. 1996. Gender and marital status differences in depression: the effects of chronic strains. Sex Roles, 34, 5/6, 299-319. 


\section{Man Guo et al.}

Zeng, Y. and Wang, Z. 2003. Dynamics of family and elderly living arrangements in China: new lessons learned from the 2000 Census. The China Review, 3, 2, 95-119. Zhan, H.J. 2004. Willingness and expectations: intergenerational differences in attitudes toward filial responsibility in China. Marriage $\mathcal{E}$ Family Review, 36, 1/2, $175^{-200 .}$

Zhang, J., Conwell, Y., Zhou, L. and Jiang, C. 2004. Culture, risk factors and suicide in rural China: a psychological autopsy case control study. Acta Psychiatrica Scandinavica, 110, 6, 430-7.

Zhang, N. J., Guo, M. and Zheng, X. 201 2. China: awakening giant developing solutions to population aging. The Gerontologist, 52, 5, 589-96.

Accepted Io November 2015; first published online I I December 2015

Address for correspondence:

Man Guo,

School of Social Work,

University of Iowa,

Iowa City,

IA 52245 , USA

E-mail: man-guo@uiowa.edu 